\title{
مatالم هرو(ى
}

\section{ميكرو RNA ها در بيمارى مالتيّل اسكلروزيس}

\author{
مجيد بيهلوان كاخكى '، عباس نيك روش "r." ناهيد رخشى'، معصومه حيدرى'
}

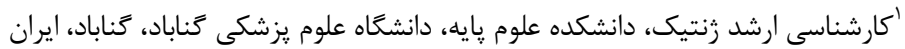

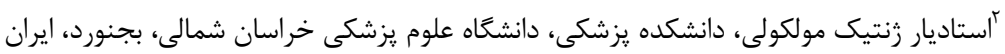

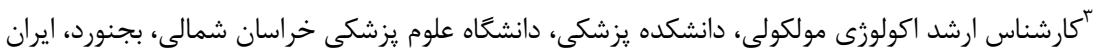

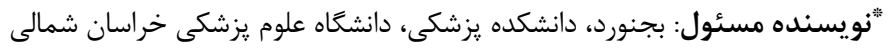

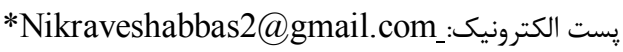

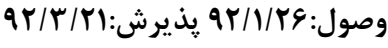

زمينه و هدف: بيمارى مالتييل /سكلروزيس (ام اس) يك بيمارى خود /يمنى تخريب كننده غلاف ميلين در دستغاه عصبى مركزى ميى

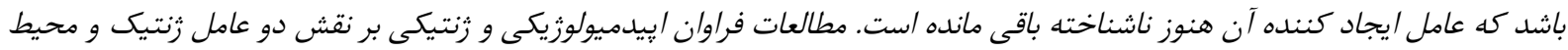

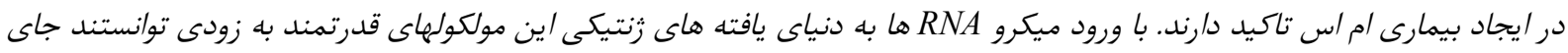

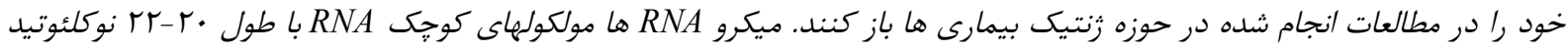

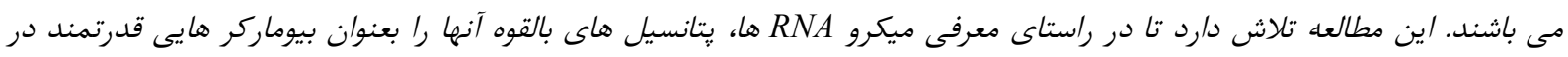

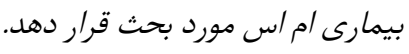

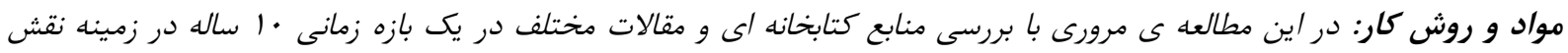

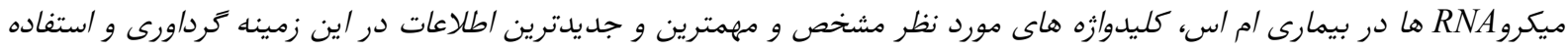
يافته ها: نتايج نشان مى دهد كه از زمان كشف ميكرو RNA ها تا كنون، در جنبه هاى مختلفى نقش آنها در بيمارى ام اس مورد /رزيابى

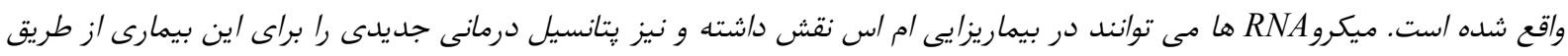
تنظيم بيان ثن هاى دركير در مسير بيماريزايى آن فراهم كنند.

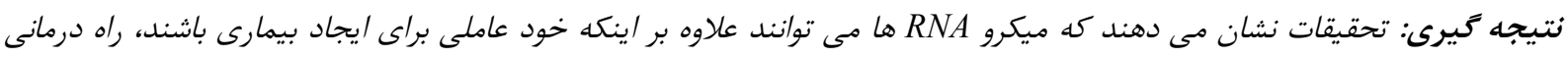

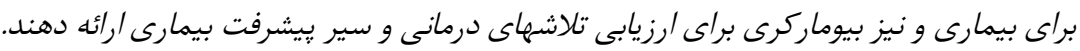

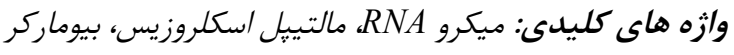

ناشناخته اى است و به همين دليل در زمره بيمـارى هـاى مقدمه

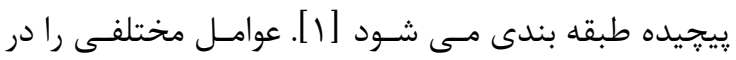

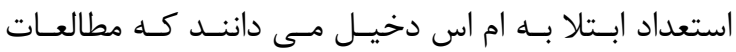
مالتيـــل اسـكلروزيس (ام اس) ' يـك بيمـارى التهـابى در

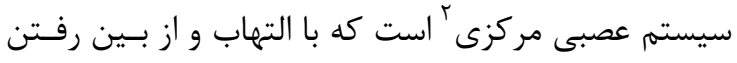
مختلف انجام شده در اين حوزه بر نقش زنتيـك و محسيط مالم

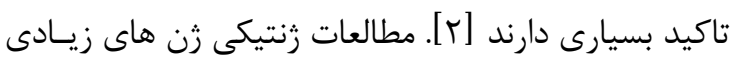

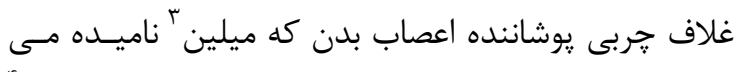
را كه در استعداد ابتلا به MS دخيل هستند، معرفى كرده و فهرست اين زن ها با مطالعات انجام شـده طــولانى تـر و كامل تر مى شود. از جمله زن هاى دخيل در اين بيمـارى

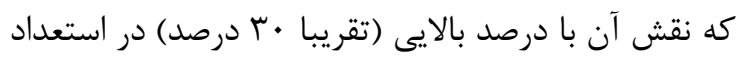
2 -CNS
3 -Myelin
4 -Etiology

-MS 
كوجى و با توجه به الكوى خاص بيانى آنها در بافت هـاى مختلف بتوان بعنوان ماركرى با خصوصيات واقعى ماركرها، براى تشخيص زودهنخام بيمارى هاى پيجزيده قرن استفاده

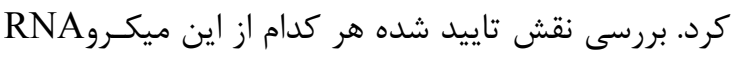

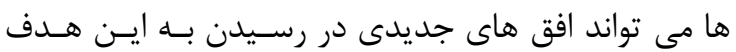

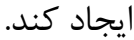

\section{خصوصيات ميكروRNA ها}

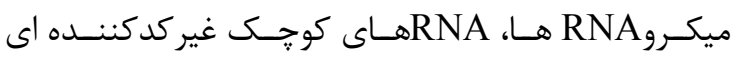

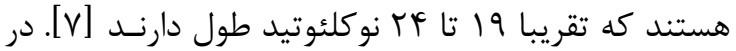

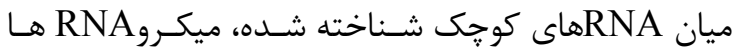
بهترين كروه طبقه بندى شده به لحاظ تعداد، تنـوع، روش

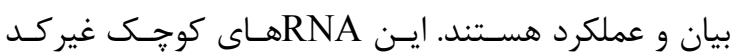

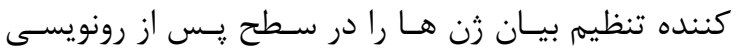

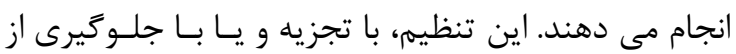

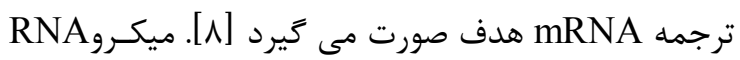

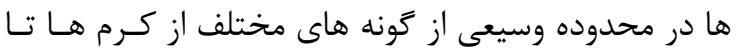

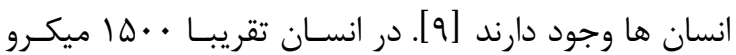

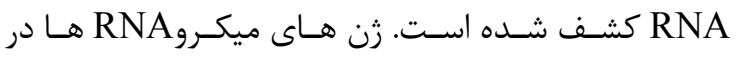

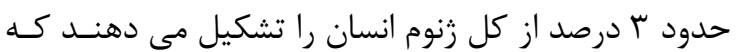

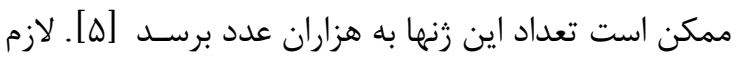

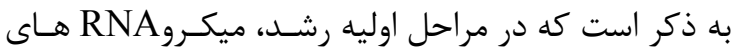

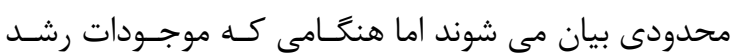
كرده و بالغ مى شوند و به انواع سلولى مختلفى تمايز مسى مئ مانى

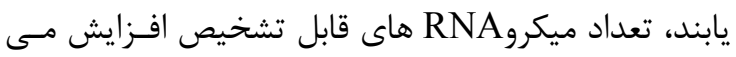

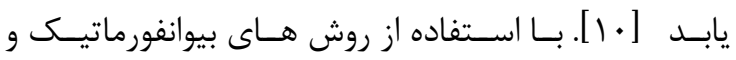

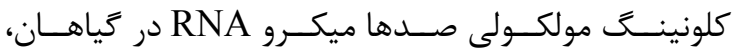
حيوانات و ويروس ها شناسايى شده است. ميكروRNA ها

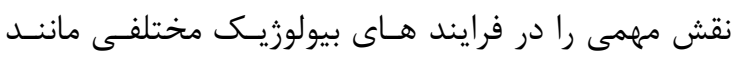

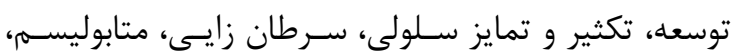

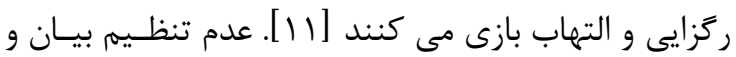

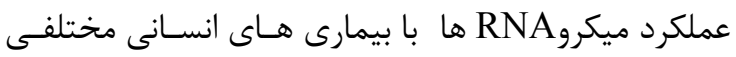

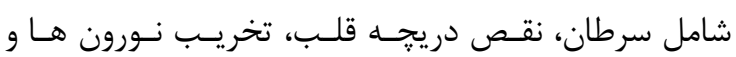

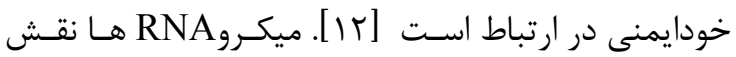

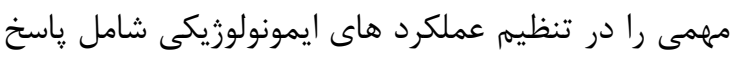

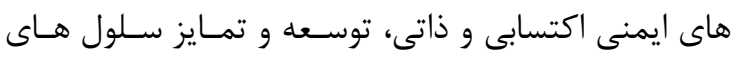

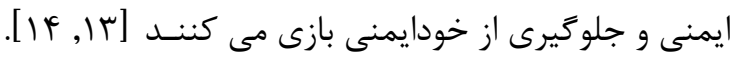

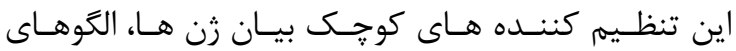

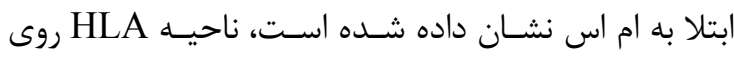

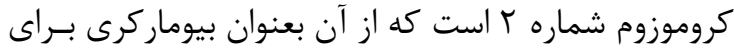

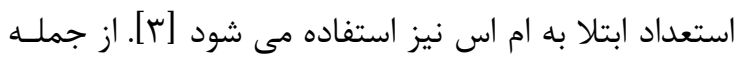

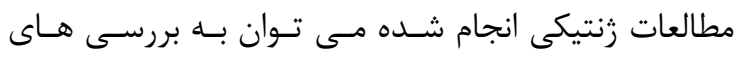

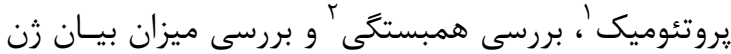
هاى كانديد اشاره نمود. بررسى هاى إيـدميولوزيك نشئسئان

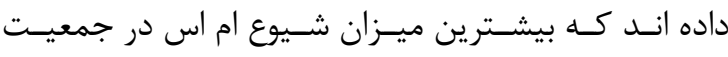

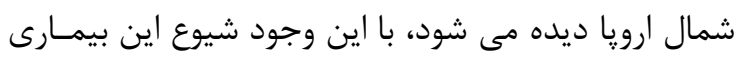

در مناطق مختلف متفاوت است [F].

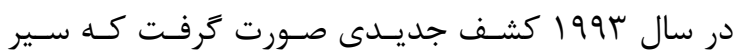

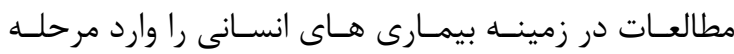

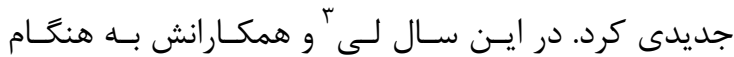

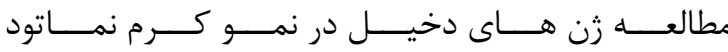
مRNA Caenorhabditis elegans lin-F كروه جديدى از RNA ها تحت عنوان RNA هاى غير كد

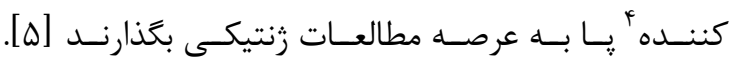

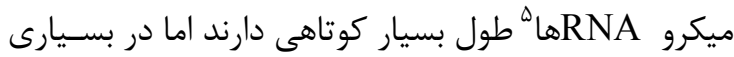
از فرايندهاى فيزيولوزيك بدن نقش هاى مهمى را ايفا مى

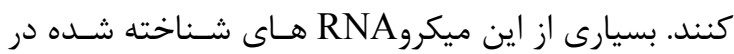

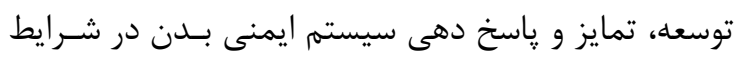

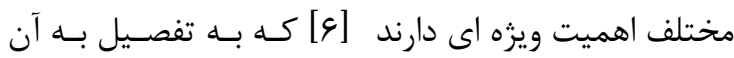

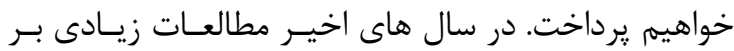

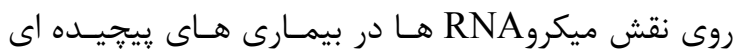
مانند سرطان ها و بيمارى هاى خود ايمنى صـورت گرفيتهـ

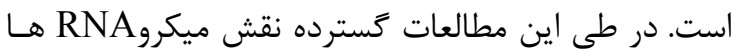
در ايمنى بدن مورد بررسى و تاييد بيشتر واقع شده اسـت.

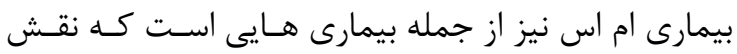
مهمم ميكروRNA ها در مراحل مختلف آن مورد تاكيد قرار

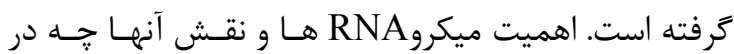

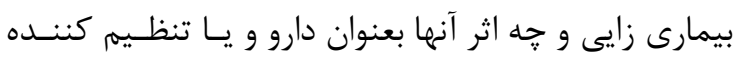

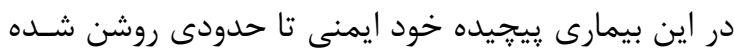

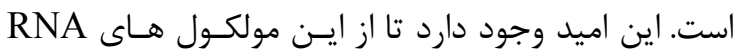

1 -Proteomics

2 -Association study

3 -lee

4- Non-coding RNAs

5 -MicroRNAs 
ايجاد كنند كه تقريبا • V نوكلئوتيد طـول دارد [19]. ايـن

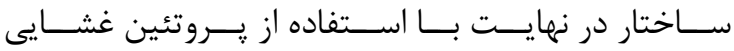

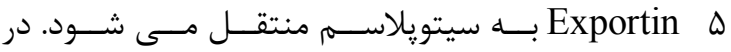

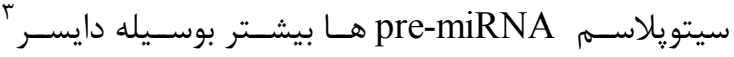
يردازش مى شوند و مولكول RNA دو رشـــه اى را ايجــاد

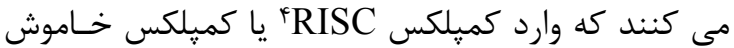

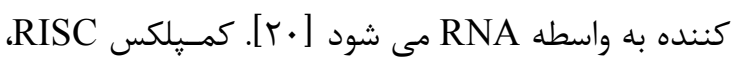
pre-miRNA اين ترتيب ميكرو RNA بالغ ايجاد مى شود. در اين هنكام

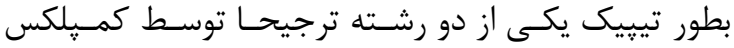

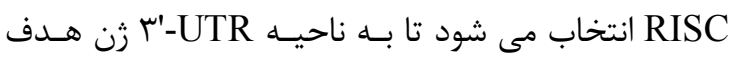
متصل شود، اما رشته ديكر معمولا تجزيـه مسى شـود. اخـر

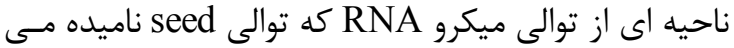

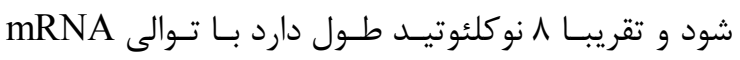
هدف خود بطور كامل جفت شود، ميكرو RNA مورد نظــ با استفاده از كميلكس يروتئينى

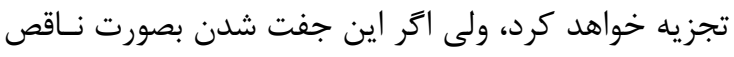
انجام شود، ميكرو RNA تنها از ترجمه

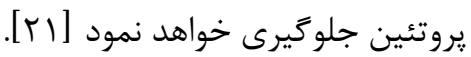

\section{نقش ميكرو RNA ها در سيستم ايمنى}

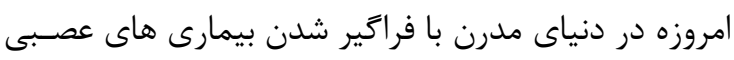

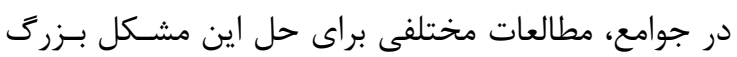

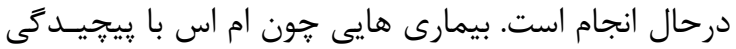
هاى خاص خود جالش بزركى را بر سر راه محققــان ايجـاد

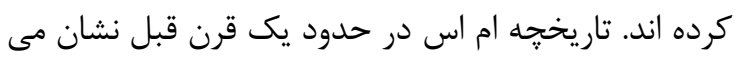
دهد كه اين بيمارى توسط يزشكان مختلف به شيوه هـاى مختلفى تحت درمان بوده است. شايد مهمترين علـت ايسن درمان هاى متفاوت تفكر يزشكان درباره علت بروز بيمارى

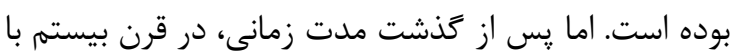
بررسى هاى انجام شده مشخص شد كه ام اس يك بيمارى

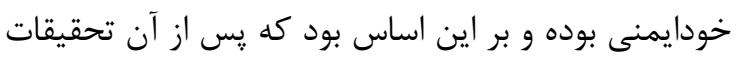

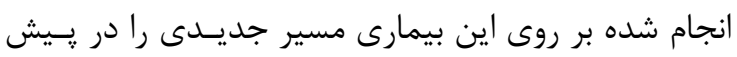
كرفت. سيستم ايمنى بدن، با اجزاء و ساختارهاى متنوع از

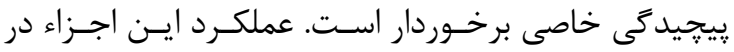

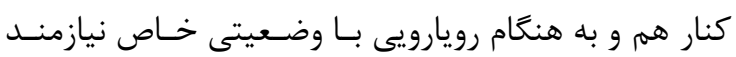

\section{3 -Dicer}

4 -RNA Induced Silencing Complex
خاصى براى بيان مانند الكوى مشخص بيانى در بافت هاى خاص و همجنين در شرايط تمايزى، بيمارى و غيره دارند. ميكرو RNA ا ما در زنوم

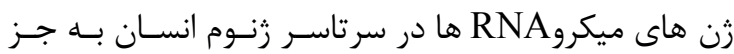

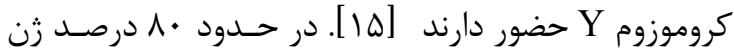
هاى ميكروRNA هاى انسانى در نواحى اينترونسى حضـور دارند كه آن ها را مى توان هم در رشته كدكننده يروتئين

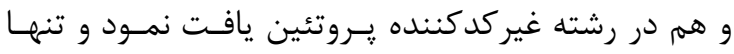

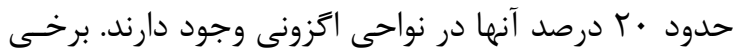

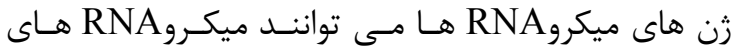

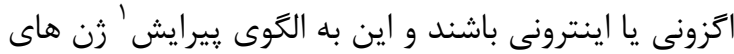

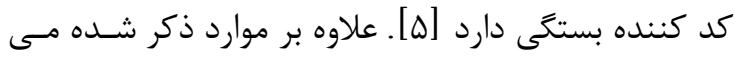

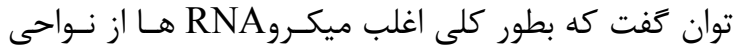
درون زنى كد مى شوند و برخى ديخر مى توانـــد بصـورت

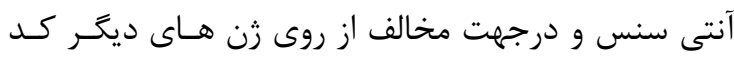

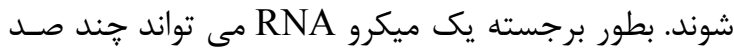
را مورد هدف قرار دهد و تصور مى شود كه بيسان

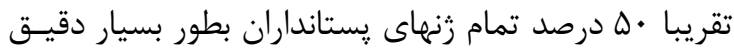

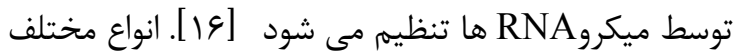
فرايند كد شدن ميكروRNA ها نشان دهنده اين است كه

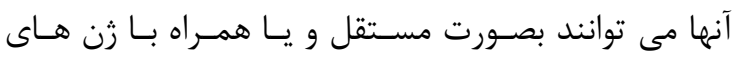

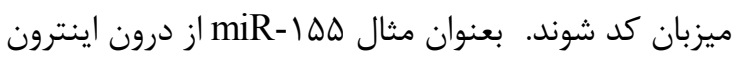

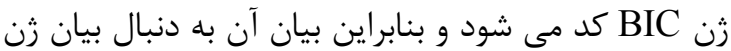

صورت مى گيرد [IV [IV

سنتز miRNA ها

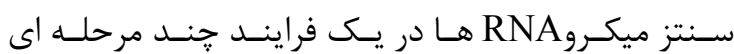
صورت مى كيرد، كه در نهايت با اتصال ميكـرو RNA بــــ

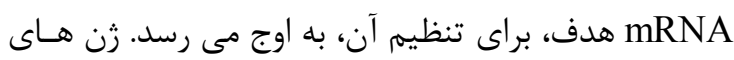

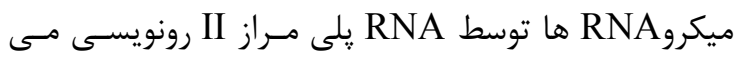

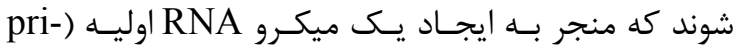

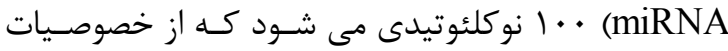

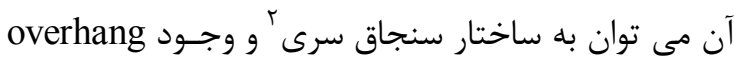

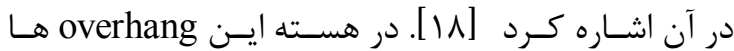

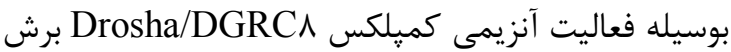

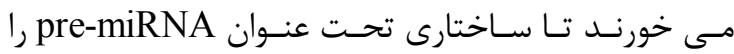



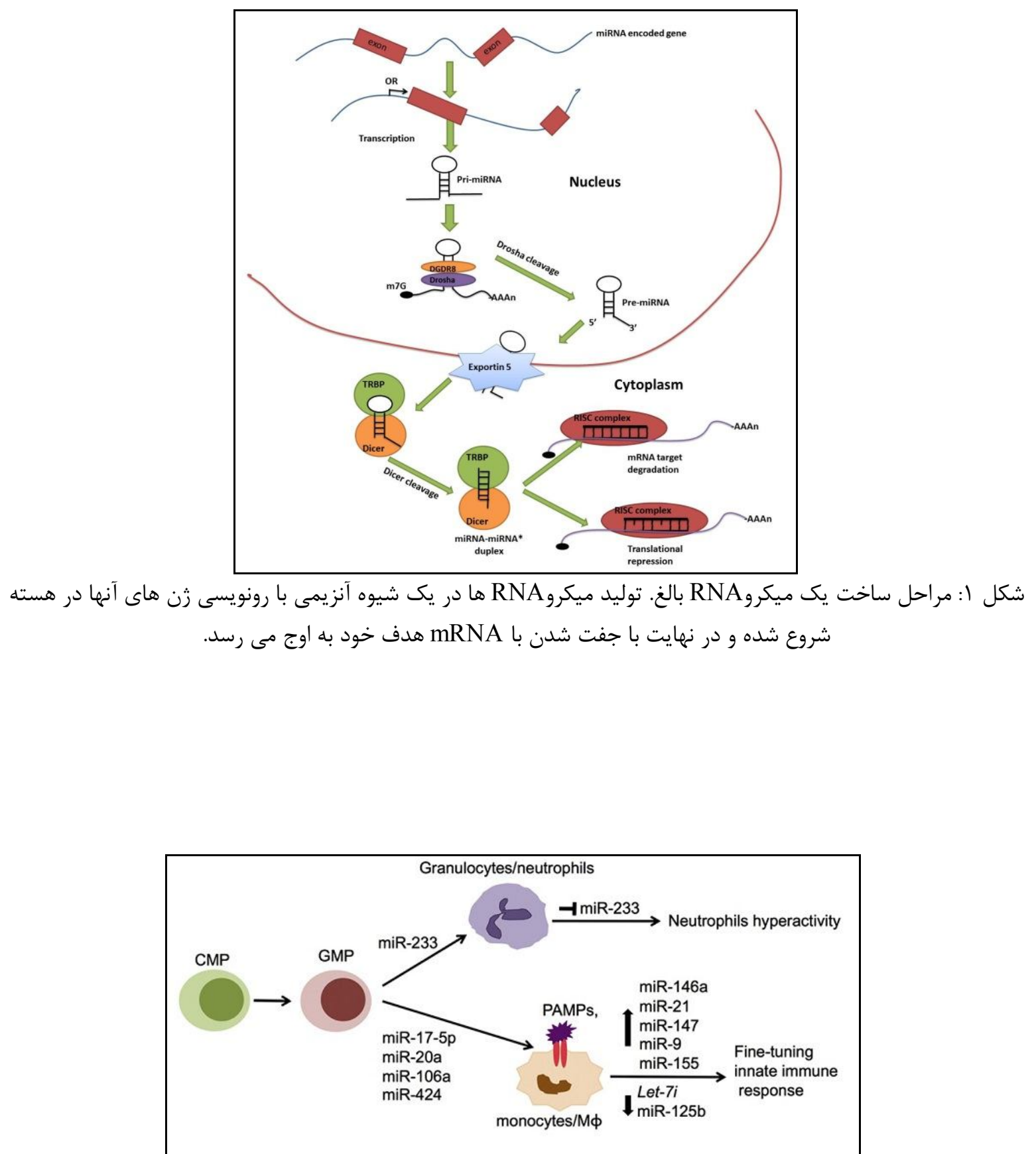

شكل r: miRNA ها در ايمنى ذاتى. اين شكل miRNA هاى مختلف را كه در تمايز و عملكرد نوتروفيل ها، مونوسيت ها و

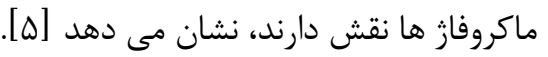




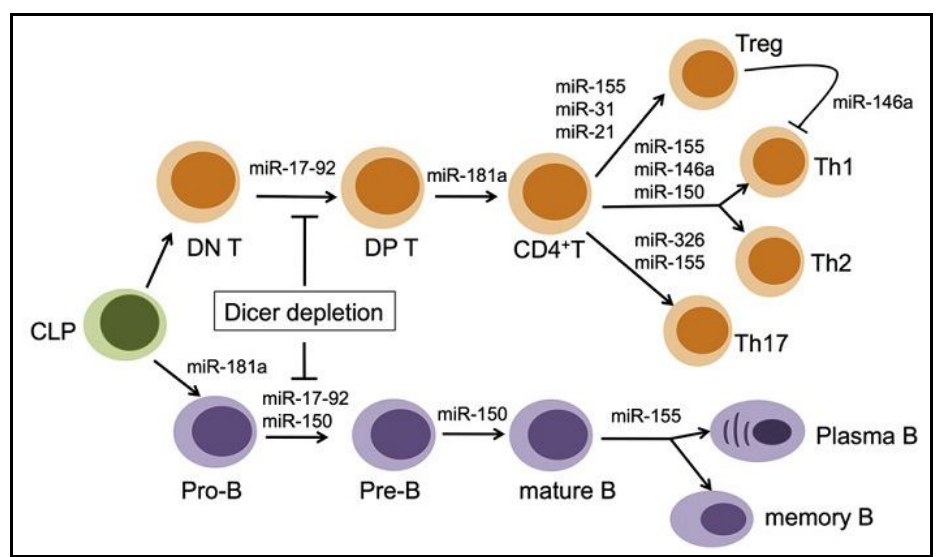

شكل r: miRNA ها در ياسخ هاى ايمنى اكتسابى. اين شكل miRNA هاى مختلفى را كه در ياسخ هاى ايمنى اكتسابى نقش

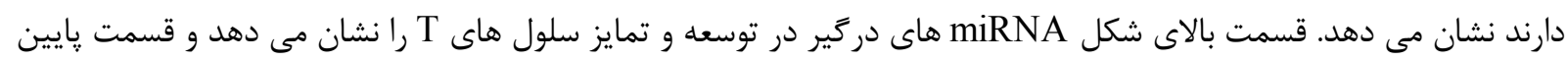

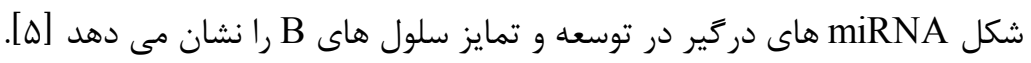

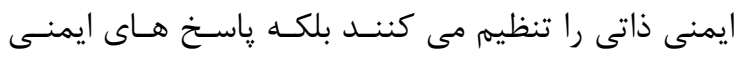

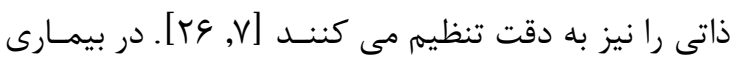

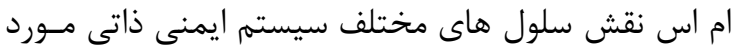

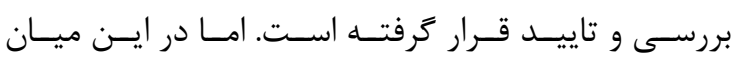

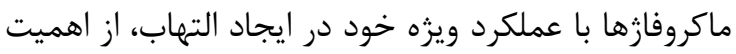

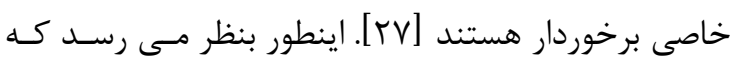

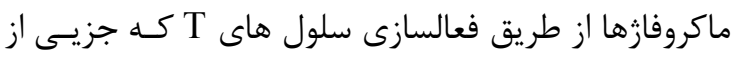

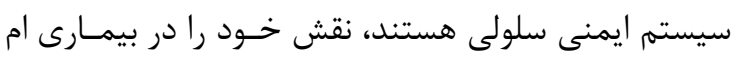

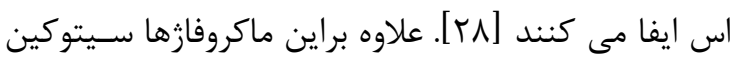

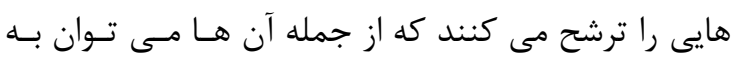

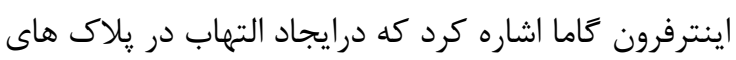

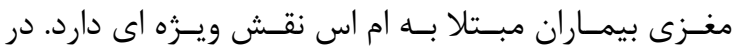
ارتباط با سلول هاى دركير در ايمنسى ذاتسى بعنـوان مثــال

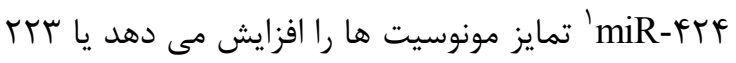
miR-

$$
\text { ها عمل مى كند [rq]. }
$$

\section{نقش ميكرو RNA ها در ايمنى اكتسابى هن}

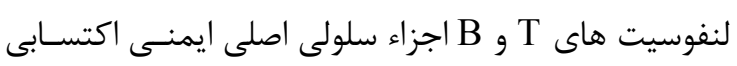

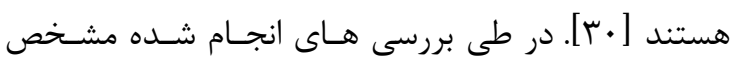

\section{1 -MicroRNA-424}

تنظيم دقيـق و توسـعه بهنَخـام سيسـتم ايمنسى اسـت. بـاــا

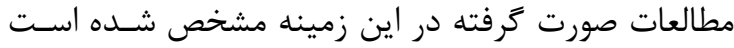

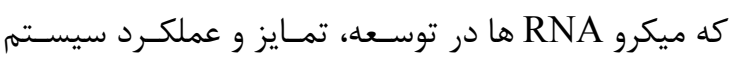

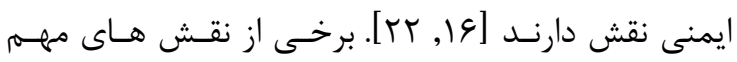

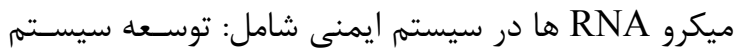

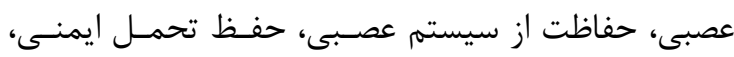

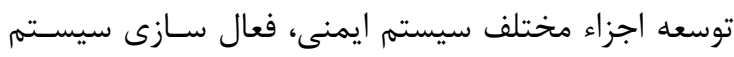
ايمنى، تنظيم عملكرد سلول هاى ايمنى، تمايز سلول هاى

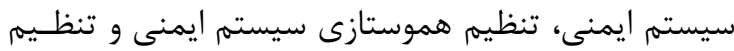

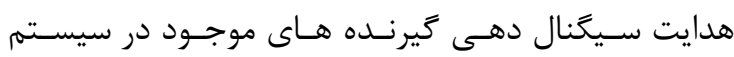

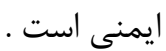
نقش ميكرو RNA ها در ايمنى ذاتى إنى

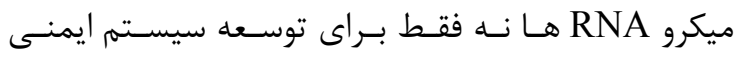

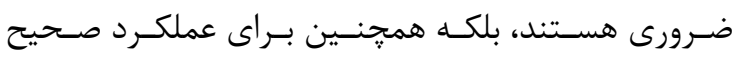

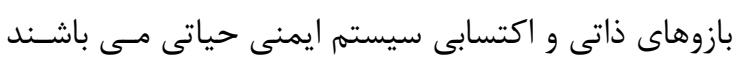

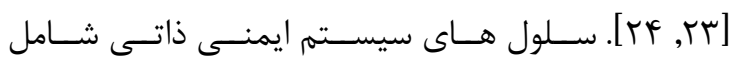

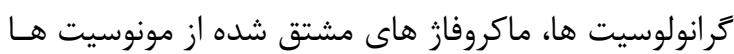

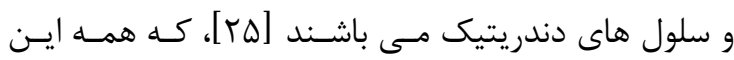

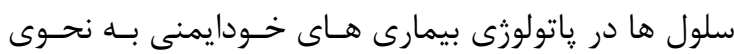

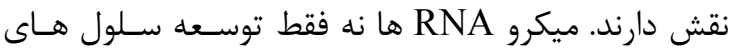


اس و بيسارى از بيمارى هاى خودايمنى ديخر معرفى مسى إسى

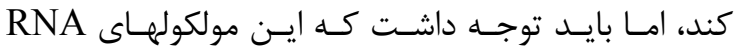

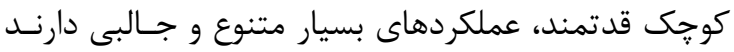

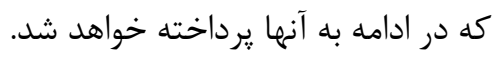
در ياره اى از موارد، ميكروRNA ها نقش خود را را با تنظيم

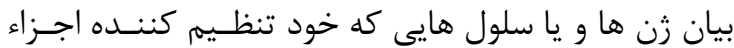

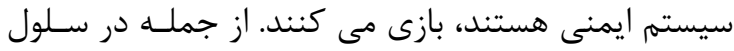

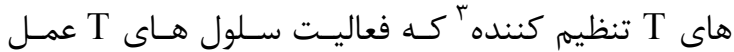
كننده را مهار مى كنند، تـا هموسـتازى سيسـتم ايمنسى و

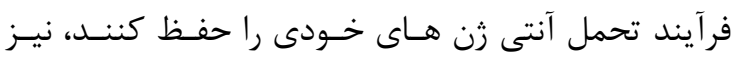

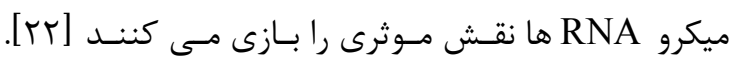

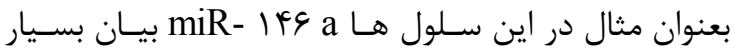

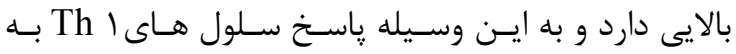

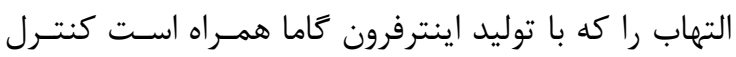

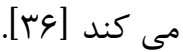

\section{ميكروRNA ها در خودايمنى} براى حفظ تحمل در برابر آنتى زنها، نقاط كنترلى زيـادى

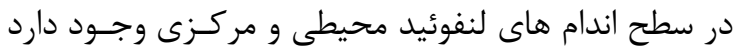

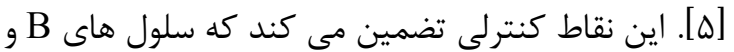
خودفعال شونده كه بطور عادى و تصادفى در طى توليد لنفوسيت ها ايجاد مى شوند، حذف و يا خاموش شوند. امـا

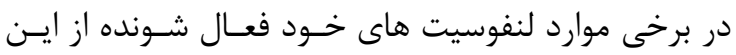
نقاط كنترلى فرار مى كنند و در بافت لنفوئيسدى محيطى دوردي

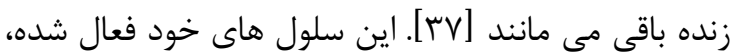

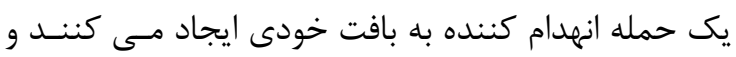

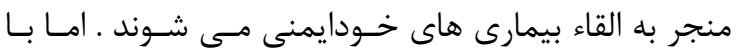
وجود اين حقيقت كه miRNA ها بشدت در سـلول هـاى لهاى سيستم ايمنى نرمال تنظيم شده اند تا هموستازى سيستم ايمنى را حفظ كنند و عملكرد ايمنى نرمال را سبب شوند، نئه اين امكان وجود دارد كه بيان تنظـيم نشــه miRNA هـا منجر به شكست تحمل ايمنى و ايجاد بيمارى هـاى خــود

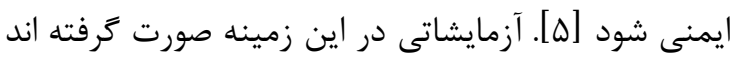

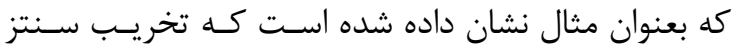
هiRNA

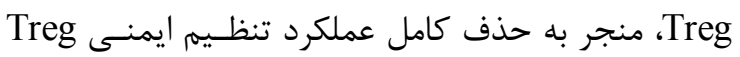

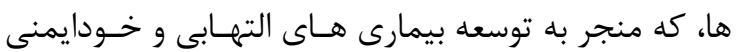

3 -T regulator ( $\mathrm{T}$ reg)
شده است كه در ياتوزنز بيمارى ام اس يكى از مراحلى كــه

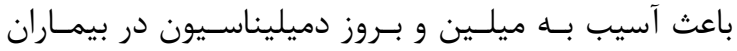

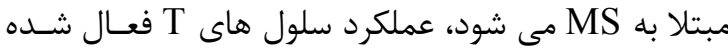

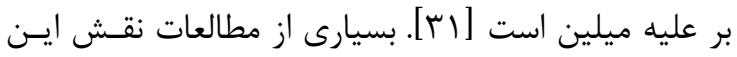

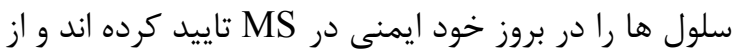

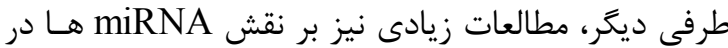

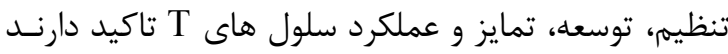

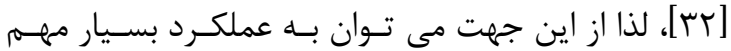

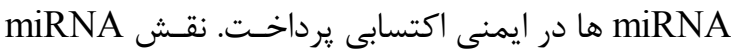
ها در تنظـيم توسـه و عملكـرد لنفوسـيت هـا، اخيـرا در

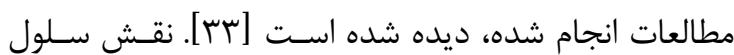
هاى T در بيمارى ام اس در مطالعات زيادى مورد بررسى إدى ديل قرار گرفته است. در اين بررسى ها سلول هاى Th1 بعنوان

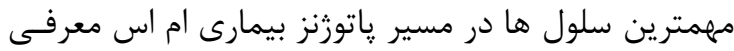

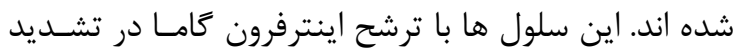

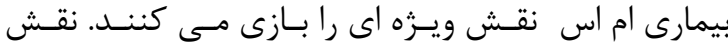

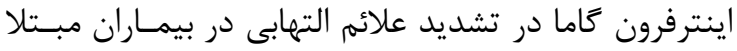

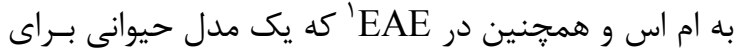

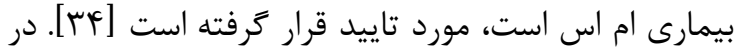

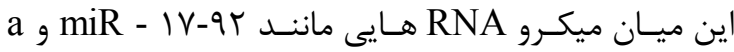

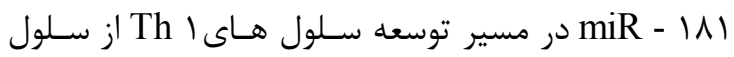
ييش ساز اوليه نقش اساسى را بازى مسى كنـــــ آن جنـان كه مشخص شـده است بلوغ سلول هـاى T بوسـيله تنظـيم طــول سـيخَنال دهـى

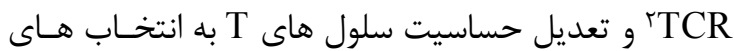

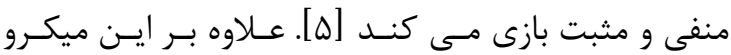

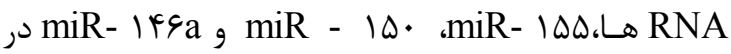

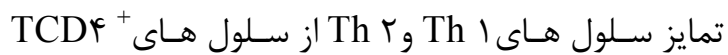
بسيار موثرند [مَّ]. حال با اين ديد مى تـوان تصـور نمـود

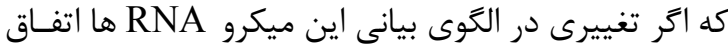
بيفتد يا اينكه تحت تاثير هرعاملى عملكرد هر كدام از آنهـا مختل شود، جه تاثيرات سوئى بر عملكـرد دقيـق سيسـتم

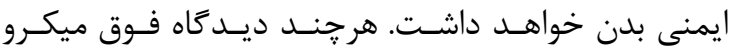
هNA

\section{1- Experimental Autoimmune Encephalomyelitis 2- T Cell Receptor}


كه اخيرا در اين زمينه انجام شده اسـت، نشـان داده شـده است.

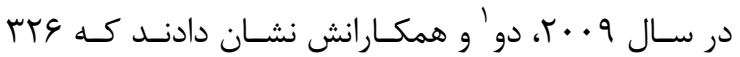
نقش مهمى را در بيمارى زايى MS بوسيله افزايش

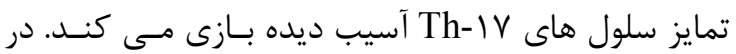

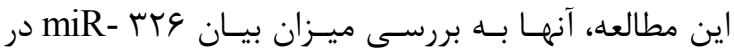

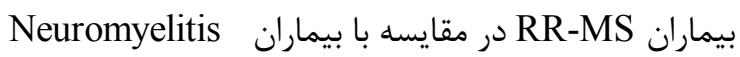
optica

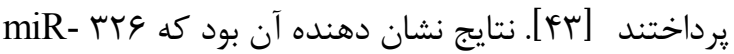
در بيمـاران RR-MS و نسه در بيمـاران Neuromyelitis optica

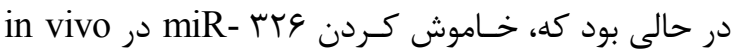
در موش EAE توليد سلول هاى Th- IV مهار مى كـرد

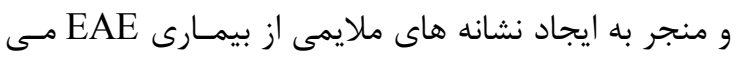

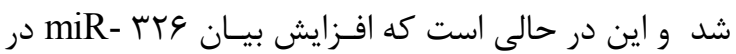

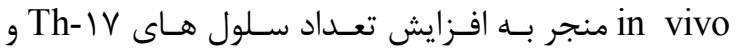

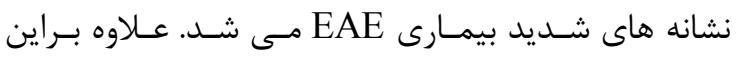

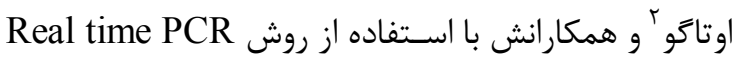

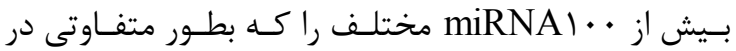

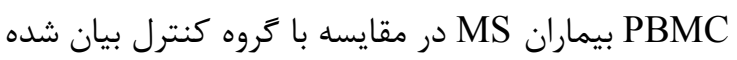

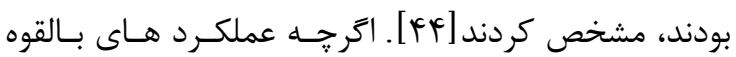
miRNA miRNA

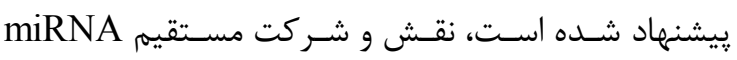
هاى تنظيم نشده در MS در بعـد وسـيعى تعيسين نشـده باقى مانده است و نياز به تحقيقات بسيار بيشترى دارد. نتيجه گَيرى

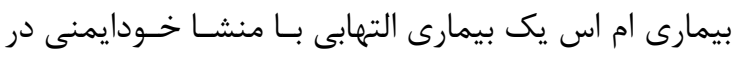

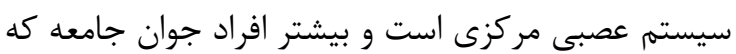
نيروى كار جامعه را تشكيل مى دهند، را مبـتلا مـى كنــد.

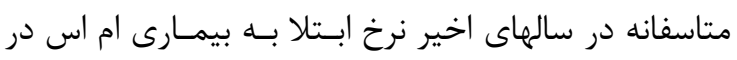

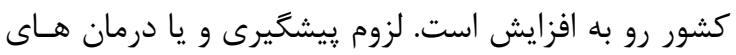
به موقع در ارتباط با اين بيمارى ييجيده بر كسى يوشـيده

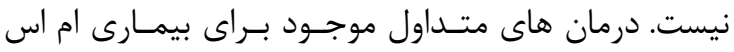

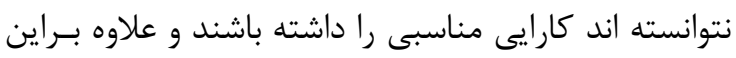

1- DU

2 -Otaegui

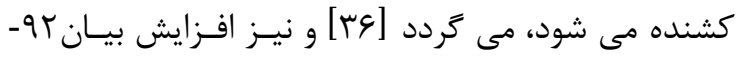
miR- IV لنفوسيت ها و بيمارى هاى خودايمنى را ايجـاد مسى كنــد

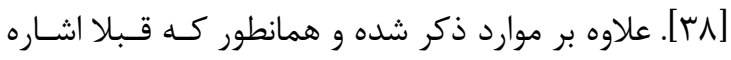
شد، اين حقيقت كه miRNA ها در تنظيم انتخاب سـلول همول هاى T)، حساسيت گيرنده هـاى سـلول هـاى T و توسعـه سلول هاى Treg در رِاسخ هاى ايمنى نرمال نقـش دارنـد،

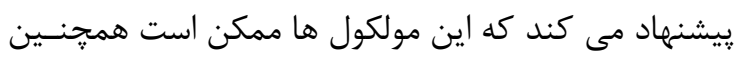

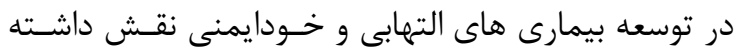

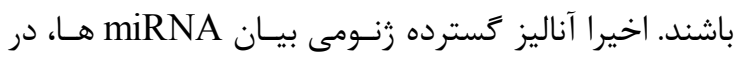

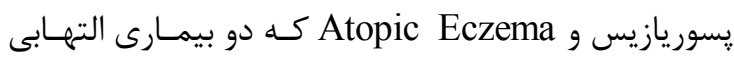
مـزمن عمــومى هسـتند، اولـين شـواهد را از ارتبـاط بــين

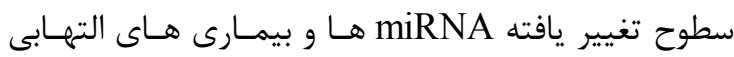

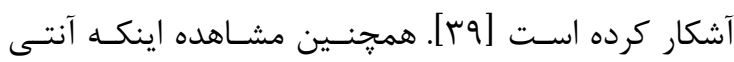
بادى هاى جدا شده از بيماران خـودايمنى، عليـه هـروتئين هاى مختلفى كه در عملكرد miRNA ها نقش دارند فعال

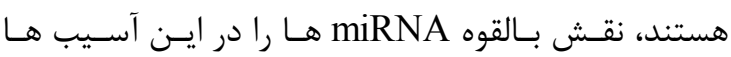
آشكار مى كند. توصـيف بيشـتر عملكـرد miRNA هـا در انواع مختلف سلول هاى ايمنى و تعيين زن هاى هدف بــه

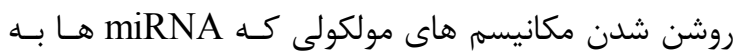

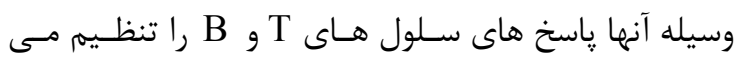
كنند، كمك خواهد كرد.

\section{ميكروRNA ها در بيمارى MS}

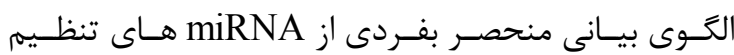

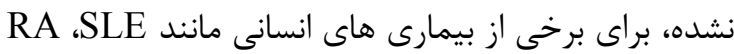

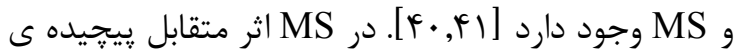
بين سلول هاى ايمنى مهاجم به مغز و سلول هاى مسـتقر

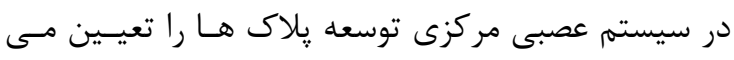

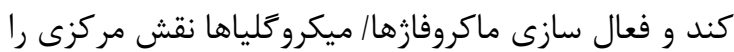

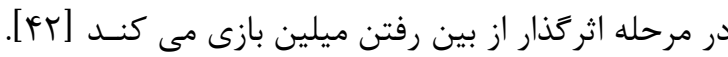

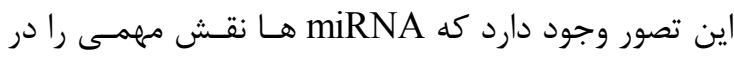
بيمارى MS بازى مى كنيند زيرا در سلول هاى ايمنسى بــه مقدار بسيار زيادى بيان مى شوند كه اين سلول ها واسـطه هاى ايجاد بيمارى هستند، و بعلاوه در سلول هاى سيستم

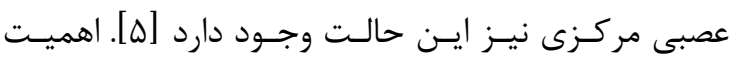
عملكردى miRNA ها در بيمارى زايى MS در مطالعـاتى مرئى 
درمـانى بــراى بيمـارى و نيـز بيومــاركرى بــــاى ارزيــابى

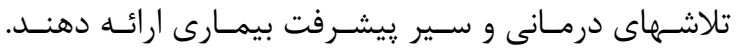
تحقيقات در زمينه استفاده از ميكروRNA ها هـهم اكنـون در بسيارى از آزمايشگاه هـاى سرتاسـر دنيـا و در سـطوح مختلف در حال انجام است. اميد مـى رود تـا در آينـده ايى دئي نزديك بتوانيم درمان هايى را بريايه ميكرو RNA ها بـراى بيمارى ام اس داشته باشيم. تشكر و قدردانى بدين وسيله از حمايت هاى دانشعاه علوم يزشكى خراسان شمالى و نيز دانشعاه علوم يزشكى گَناباد كمال تشكر و و قدردانى را داريم.

\section{References}

1. Gourraud PA, Harbo HF, Hauser SL, Baranzini SE, The genetics of multiple sclerosis: an up to date review. Immunological reviews 2012;248(1):87-103.

2. Baranzini SE, Nickles D. Genetics of multiple sclerosis: swimming in an ocean of data, Current Opinion in Neurology 2012;25(3):239-245.

3. Cree BA, Rioux JD, McCauley JL, Gourraud PA, Goyette P, McElroy J, "et al", A major histocompatibility Class I locus contributes to multiple sclerosis susceptibility independently from HLA-DRB1*15:01. PLoS One 2010;5(6):e11296.

4. Kurtzke JF, Geographic distribution of multiple sclerosis: an update with special reference to Europe and the Mediterranean region, Acta Neurologica Scandinavica 1980;62(2):65-80.

5. Dai R, Ahmed SA, MicroRNA, a new paradigm for understanding immunoregulation, inflammation, and autoimmune diseases, Transl Res 2011 Apr;157(4):163-79.

6. Junker A, Krumbholz M, Eisele S, Mohan H, Augstein F, Bittner R, " et al", MicroRNA profiling of multiple sclerosis lesions identifies modulators of the regulatory protein CD47, Brain 2009;132(12): 3342-3352.

7. Carissimi C, Fulci V, Macino G. MicroRNAs: novel regulators of immunity, Autoimmun Rev. 2009 May;8(6):520-524.

8. Guerau-de-Arellano M, Alder H, Ozer HG, Lovett-Racke A, Racke MK, miRNA profiling for biomarker discovery in multiple sclerosis: From microarray to deep sequencing, Journal of Neuroimmunology. 2012 7/15/;248(1-2):32-39.

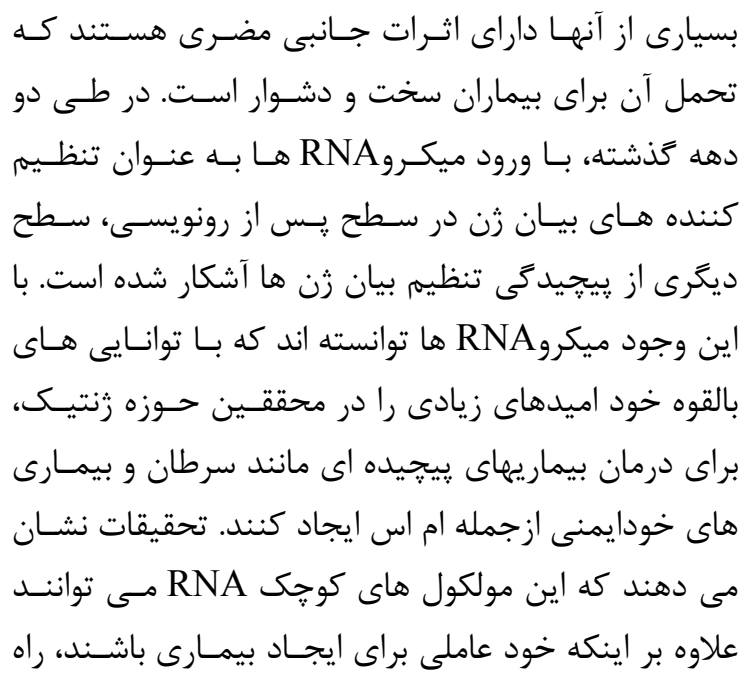

9. Martinelli-Boneschi F, Fenoglio C, Brambilla P, Sorosina M, Giacalone G, Esposito F, "et al", MicroRNA and mRNA expression profile screening in multiple sclerosis patients to unravel novel pathogenic steps and identify potential biomarkers, Neuroscience letters 2012;508(1):48.

10. Benes V, Castoldi M, Expression profiling of microRNA using real-time quantitative PCR, how to use it and what is available, Methods 2010;50(4):244-249.

11. Garzon R, Calin GA, Croce CM. MicroRNAs in cancer, Annual review of medicine 2009;60:167-179.

12. Tufekci KU, Oner MG, Genc S, Genc K. MicroRNAs and multiple sclerosis, Autoimmune diseases, 2011; 807426(1): 1-27.

13. Pauley KM, Chan EKL, MicroRNAs and their emerging roles in immunology, Annals of the New York Academy of Sciences 2008;1143(1):226-239.

14. Taganov KD, Boldin MP, Baltimore D, MicroRNAs and immunity: tiny players in a big field, Immunity 2007;26(2):133-137.

15. Fenoglio C, Cantoni C, De Riz M, Ridolfi E, Cortini F, Serpente M,“ et al", Expression and genetic analysis of miRNAs involved in CD4+ cell activation in patients with multiple sclerosis, Neurosci Lett 2011 Oct 17;504(1):9-12.

16. Junker A, Hohlfeld R, Meinl E, The emerging role of microRNAs in multiple sclerosis, Nat Rev Neurol 2011 Jan;7(1):56-59.

17. Eis PS, Tam W, Sun L, Chadburn A, Li Z, Gomez MF, "et al", Accumulation of miR-155 and BIC RNA in human B cell lymphomas, Proceedings of the National Academy of 
Sciences of the United States of America 2005;102(10):3627-3632.

18. Kim VN, MicroRNA biogenesis: coordinated cropping and dicing, Nature Reviews Molecular Cell Biology 2005;6(5):376-385.

19. Bandiera S, Hatem E, Lyonnet S, Henrion-Caude A, microRNAs in diseases: from candidate to modifier genes, Clinical genetics 2010;77(4):306-313.

20.Zeng Y, Cullen BR, Structural requirements for pre-microRNA binding and nuclear export by Exportin 5, Nucleic acids research 2004;32(16):4776-4785.

21. Bartel DP, MicroRNAs: target recognition and regulatory functions, Cell 2009;136(2):215233.

22. Carissimi C, Fulci V, Macino G, MicroRNAs: novel regulators of immunity, Autoimmunity reviews 2009 05/;8(6):520-524.

23.Bi Y, Liu G, Yang R. MicroRNAs: novel regulators during the immune response, Journal of cellular physiology, 2009;218(3):467-472.

24. O'Connell RM, Rao DS, Chaudhuri AA, Baltimore D, Physiological and pathological roles for microRNAs in the immune system, Nature Reviews Immunology 2010;10(2):111122.

25. Błach-Olszewska Z, Innate immunity: cells, receptors, and signaling pathways, Archivum immunologiae et therapiae experimentalis 2005;53(3):245-253.

26. Sioud M, RNA interference and innate immunity, Advanced drug delivery reviews, 2007;59(2):153-163.

27. Brück W, Sommermeier N, Bergmann M, Zettl U, Goebel HH, Kretzschmar HA, "et al”, Macrophages in multiple sclerosis, Immunobiology. 1996;195(4):588-600.

28. Severson C, Hafler D, T-cells in multiple sclerosis, Molecular Basis of Multiple Sclerosis 2010:75-98.

29. Rosa A, Ballarino M, Sorrentino A, Sthandier $\mathrm{O}$, De Angelis FG, Marchioni M, "et al", The interplay between the master transcription factor PU, 1 and miR-424 regulates human monocyte/macrophage differentiation, Proceedings of the National Academy of Sciences, 2007;104(50):19849-19854.

30. Janeway CA, Travers P, Walport M, Capra JD, Immunobiology: the immune system in health and disease: Current Biology; 2001:125132

31. Comabella M, Khoury SJ, Immunopathogenesis of multiple sclerosis, Clinical Immunology 2012;142(1):2-8.
32. Turner M, Vigorito E, Regulation of B-and Tcell differentiation by a single microRNA, Biochemical Society Transactions 2008;36:531533.

33. Lu LF, Liston A, MicroRNA in the immune system, microRNA as an immune system, Immunology 2009;127(3):291-298.

34. Popko B, Corbin JG, Baerwald KD, Dupree J, Garcia AM, The effects of interferon- $\gamma$ on the central nervous system, Molecular neurobiology 1997;14(1):19-35.

35. Rodriguez A, Vigorito E, Clare S, Warren MV, Couttet P, Soond DR, "et al", Requirement of bic/microRNA-155 for normal immune function, Science Signalling 2007;316(5824):608-611.

36. Lu LF, Boldin MP, Chaudhry A, Lin LL, Taganov KD, Hanada T, "et al", Function of miR-146a in controlling Treg cell-mediated regulation of Th1 responses, Cell. 2010;142(6):914-929.

37. Goodnow CC, Multistep pathogenesis of autoimmune disease, Cell, 2007;130(1):25-35.

38. Xiao C, Srinivasan L, Calado DP, Patterson HC, Zhang B, Wang J, "et al", Lymphoproliferative disease and autoimmunity in mice with increased miR-17-92 expression in lymphocytes, Nature immunology 2008;9(4):405-414.

39.Zibert JR, Løvendorf MB, Litman T, Olsen J, Kaczkowski B, Skov L, MicroRNAs and potential target interactions in psoriasis, Journal of dermatological science 2010;58(3):177-185.

40. Dai Y, Huang YS, Tang M, Lv TY, Hu CX, Tan YH, "et al", Microarray analysis of microRNA expression in peripheral blood cells of systemic lupus erythematosus patients, Lupus, 2007;16(12):939-946.

41. Pauley KM, Cha S, Chan EKL, MicroRNA in autoimmunity and autoimmune diseases, Journal of autoimmunity 2009;32(3-4):189-194.

42. Li H, Cuzner M, Newcombe J, Microglia derived macrophages in early multiple sclerosis plaques, Neuropathology and applied neurobiology 2008;22(3):207-215.

43. Du C, Liu C, Kang J, Zhao G, Ye Z, Huang S, "et al", MicroRNA miR-326 regulates TH-17 differentiation and is associated with the pathogenesis of multiple sclerosis, Nat Immunol 2009 Dec;10(12):1252-1259.

44. Otaegui D, Baranzini SE, Armañanzas R, Calvo B, Muñoz-Culla M, Khankhanian P, “et al",Differential micro RNA expression in PBMC from multiple sclerosis patients, PLoS One. 2009;4(7):e6309. 
Review Article

\title{
MicroRNAs in Multiple Sclerosis
}

\author{
Pahlevan Kakhki $M^{l}$, Nikravesh $A^{2}{ }^{*}$, Rakhshi $N^{3}$, Heidary $M^{l}$
}

${ }^{1}$ MS.c in Genetics, Department of Basic Sciences, Gonabad University of Medical Sciences, Gonabad, Iran.

${ }^{2} \mathrm{Ph}$.D in Molecular Genetics, School of Medicine, North Khorasan University of Medical Sciences, Bojnurd, Iran.

${ }^{3}$ MS.c in Molecular Ecology, Department of molecular Sciences, School of Medicine, North Khorasan University of Medical Sciences, Bojnurd, Iran.

\author{
*Corresponding Author: \\ North Khorasan University of \\ Medical Sciences, Bojnurd, \\ Iran \\ Email: \\ nikraveshabbas2@gmail.com
}

Submitted:15 Apr 2013

Accepted:11 June 2013

\begin{abstract}
Background \& Objectives: Multiple Sclerosis (MS) is a potentially devastating disease in the central nervous system with an unknown etiology. Many epidemiologic and genetic studies are revealed that both genetic and environment can influence the susceptibility of MS. When microRNAs are introduced to molecular genetic world, they could establish their position in genetic studies. MiRNAs are small (19-24 nucleotides) noncoding RNAs. Here, we are trying to introduce the role of miRNAs in MS and their potentials to serve as biomarkers.
\end{abstract}

Material \& Methods: In this study we reviewed some different articles in a 10-years period about the role of miRNAs in MS. Then we selected the specific keywords and the most recent data were collected in this field.

Results: The results show that many studies are performed on the role of miRNAs in various aspects of miRNAs in MS. In addition, miRNAs can be involved in the pathogenesis of MS, as well as they have some new therapeutic potential for MS through the gene expression regulation.

Conclusion: Our results suggest that beside the role of miRNAs in MS pathogenesis, they have some therapeutic potential for MS. As well as, they can serve as biomarkers to evaluate disease progression and therapeutic efforts.

Keywords: MicroRNAs, Multiple Sclerosis, Biomarker 